\title{
Primary Drug-Resistance Pattern and Trend in Elderly Tuberculosis Patients in Shandong, China, from 2004 to 2019
}

This article was published in the following Dove Press journal: Infection and Drug Resistance

\author{
Qiqi $\mathrm{An}^{\prime}$ \\ Wanmei Song' \\ Jinyue Liu $^{2}$ \\ Ningning $\mathrm{TaO}^{3}$ \\ Yao Liu ${ }^{4}$ \\ Qianyun Zhang' \\ Tingting $\mathrm{Xu}^{4}$ \\ Shijin Li $\mathbb{B D}^{\prime}$ \\ Siqi Liu' \\ Yifan $\mathrm{Li}^{4}$ \\ Chunbao $\mathrm{Yu}^{5}$ \\ Huaichen $\mathrm{Li}^{1,4,6}$ \\ 'Department of Respiratory Medicine, \\ Shandong Provincial Hospital, Cheeloo \\ College of Medicine, Shandong \\ University, Jinan, Shandong 2500I2, \\ People's Republic of China; ${ }^{2}$ Intensive \\ Care Unit, Shandong Provincial Third \\ Hospital, Jinan, Shandong I0019I, \\ People's Republic of China; ${ }^{3}$ Peking Union \\ Medical College, Beijing 100005, People's \\ Republic of China; ${ }^{4}$ Department of \\ Respiratory Medicine, Shandong \\ Provincial Hospital Affiliated to Shandong \\ First Medical University, Jinan, Shandong \\ 25002I, People's Republic of China; \\ ${ }^{5}$ Department of Respiratory Medicine, \\ Shandong Provincial Chest Hospital, \\ Jinan, Shandong 2500I3, People's \\ Republic of China; ${ }^{6}$ Shandong University \\ of Traditional Chinese Medicine, Jinan, \\ Shandong 250355, People's Republic of \\ China
}

Correspondence: Chunbao Yu; Huaichen Li Email 13505412137@I39.com; lihuaichen@163.com
Background: With an aging population, China is facing a huge burden of elderly patients with drug resistant tuberculosis (DR-TB), which has become a significant obstacle for the global TB control. There is still little study on DR-TB in the elderly in China so far. Thus, more research on the epidemiological characteristics and trend of primary DR-TB among the elderly will be necessary. Methods: A retrospective study was conducted in Shandong, China from 2004 to 2019. We collected 12,661 primary TB cases, of which 4368 elderly ( $\geq 60$ years) primary TB cases were involved. Clinical characteristics including age, sex, cavity, smoking, drinking, comorbidity and drug susceptibility data were collected from 36 TB prevention and control institutions of Shandong Province. Sputum samples were collected by each surveillance site, and examined in the TB Reference Laboratory of SPCH. Descriptive statistical analysis, chi-square and linear regression were used for analyzing.

Results: Among 4368 elderly patients with primary TB, the DR-TB and multi-resistant tuberculosis (MDR-TB) accounted for 17.19\% and 2.29\%, respectively. During 2004-2019, the proportions of MDR-TB, polydrug resistant tuberculosis (PDR-TB), rifampin (RFP)-resistance increased by $160.00 \%, 18.18 \%, 231.82 \%$, respectively and the rate of DR-TB among elderly patients with primary cavitary TB increased by $255 \%$. Among the elderly with primary DR-TB during 2004-2019, the proportion of male (from 85.19 to 89.06 ), cavity (from 7.41 to 46.88 ), RFP-resistance (from 3.70 to 21.88), and streptomycin (SM)-resistance (from 37.04 to 62.5 ) increased significantly $(\mathrm{P}<0.05)$. And the proportion of female (from 14.81 to 10.94$)$, non-cavity (from 92.59 to 32.81 ), INH-resistance (from 66.67 to 57.81 ) decreased significantly $(\mathrm{P}<0.05)$.

Conclusion: Among the elderly, the proportions of MDR-TB, PDR-TB, RFP-resistance and cavitary DR-TB increased significantly. The pattern of DR-TB changed from female, noncavity and INH-resistant groups to male, cavity, RFP or SM-resistant groups. For a better control on the elderly DR-TB in the future, we should pay more attention to male, smoking, drinking, chronic obstructive pulmonary disease (COPD) and diabetes subgroups and take targeted measures to control these subgroups.

Keywords: primary DR-TB, the elderly, epidemiology, chi-square regression, linear regression

\section{Introduction}

Tuberculosis (TB) is one of the top 10 causes of death and the main cause from an infectious disease around the world. ${ }^{1}$ Millions of people keep on falling sick with TB each year around the world. Drug-resistant TB (DR-TB) plays an important role in public health. ${ }^{1}$ The World Health Organization (WHO) estimated that there were an estimated 484,000 incident cases of multi-resistant 
/rifampin-resistant tuberculosis (MDR/RR-TB) in 2018 all over the world. China was one of the countries that accounted for almost half of the world's cases of MDR/ RR-TB. ${ }^{1,2}$ Global Burden of Diseases, Injuries, and Risk Factors data for tuberculosis (1990-2016) showed that if current trends in tuberculosis incidence continue, few countries are likely to meet the sustainable development goal (SDG) target to end the tuberculosis epidemic by 2030. ${ }^{3}$ MDR-TB, extensively drug-resistant TB (XDR TB), and other resistance beyond XDR tuberculosis are a major threat to global tuberculosis control. ${ }^{4}$

China has the largest population in the world, and is facing the prominent problem of population aging. Until the end of 2012 , the elderly population ( $\geq 60$ years of age) in China were 194 million, which accounted for $14.3 \%$ of the total population. By 2030, the elderly population in China is predicted to reach 400 million. ${ }^{5}$ With the population aging, there will be many problems that China might face in the future, including the health of aging people. TB plays an important role in the health of the old adults. ${ }^{6}$ A study showed that tuberculosis deaths were higher among old adults than younger. ${ }^{7}$ Meanwhile some studies showed that old age was a significant risk factor for developing MDRTB. ${ }^{8}$ Older adults provide society's carers, community leaders and mentors, and are important in educating the younger generation. Attaching importance to TB prevention, active TB case finding and treatment among the elderly will exert positive cascading influence through families, communities and societies. ${ }^{6}$ DR-TB is still a crisis globally, especially MDR-TB or XDR-TB. ${ }^{9}$ Besides, the rate of primary drug resistance is regarded as an epidemiological indicator for long-term surveillance of the quality of tuberculosis treatment in the community. ${ }^{10}$ The primary DR-TB is very important in the transmission of TB. It means that we should put our sights on primary tuberculosis among the elderly, especially DR-TB, to face the problem which the aging population will bring. Previous studies on elderly TB in China showed that an aging population had a higher TB incidence rate and risk to develop TB disease, ${ }^{11-13}$ Nevertheless, the studies on DR-TB in the elderly are few. Therefore, we investigated epidemiological characteristics and trend of primary DR-TB among the elderly in this study.

\section{Materials and Methods}

\section{Study Area and Study Design}

This study was carried out in Shandong, which lies on the east coast of China and is the second largest province in
China. There are 17 municipalities and 140 counties (districts) in Shandong. This retrospective cohort study was conducted from 2004 to 2019, which collected 12,661 primary TB case-patients in Shandong to evaluate the epidemiological characteristics and trend among the elderly DR-TB.

\section{Study Population and Data Collection}

We conducted the retrospective study of primary TB patients $(12,661)$ with drug-susceptibility testing (DST) results, of which 4368 were elderly and 8293 were non-elderly. The study acquired these cases from 36 TB prevention and control institutions of Shandong Province, China, from January 1, 2004 to December 31, 2019. 2 province-level hospitals (Shandong Provincial Hospital and Shandong Provincial Chest Hospital), 13 municipal-level and 21 county-level local health departments were engaged in monitoring of DRTB from 2004 to 2019. All mycobacterium tuberculosis cases involved in this study were consecutive cultureconfirmed, susceptibility to first line anti-TB drugs (isoniazid, rifampin, ethambutol, and streptomycin) was identified by DST. Trained research clinicians collected data on demographic and clinic information (sex, smoking, drinking, cavity, chronic obstructive pulmonary disease(COPD) and diabetes) by reviewing the medical records of these TB patients and acquiring their drug susceptibility test results along with the corresponding sociodemographic and clinical information using a standard case report form from 2 province-level hospitals (Shandong Provincial Hospital and Shandong Provincial Chest Hospital), 13 municipal-level and 21 county-level local health departments. The elderly and non-elderly refer to the people more or less than 60 years. Smoker (or drinker) refer to the people who have been smoking (or drinking) for 6 months or above, or those who were still smoking (or drinking) or had stopped smoking (or drinking) for less than 6 months before TB diagnosis. Drinking means more than 2 standard alcohol beverages per day. Non-smoker and non-drinker refer to the people who had never smoked or never drunk, respectively.

\section{Laboratory Methods}

All sputum samples were collected from suspected sites of involvement. Then these samples were sent to the TB Reference Laboratory of SPCH for further detection. All samples were cultured on Löwenstein-Jensen (LJ) culture medium, and then growing colonies were sent for further identification and DST. Para-nitro benzoic acid (PNB), Thiophene-2-carboxylic acid hydrazide (TCH) medium tubes, 16S rRNA gene sequence analysis (MicroSeq ID Microbial 
Identification Software (version 2.0); Applied Biosystems, Foster City, CA, USA) ${ }^{14}$ were used for identification of the species M. tuberculosis. The susceptibility to four first-line drugs (rifampicin, isoniazid, streptomycin, and ethambutol) was tested by the proportional method on Löwenstein-Jensen (LJ) culture medium according to the WHO guidelines. ${ }^{15}$ The concentration of drugs were as follows: $0.2 \mu \mathrm{g} / \mathrm{mL}$ (isoniazid, $\mathrm{INH}$ ), $40 \mu \mathrm{g} / \mathrm{mL}$ (rifampin, RFP), $10 \mu \mathrm{g} / \mathrm{mL}$ (streptomycin, $\mathrm{SM}), 2 \mu \mathrm{g} / \mathrm{mL}$ (ethambutol, EMB). ${ }^{16}$

\section{Quality Control}

Quality assessment and data extraction were completed by two professional investigators, respectively. The Superior TB National Reference Laboratory in SPCH implemented the external quality assessment regularly for all laboratories in our study.

\section{Inclusion and Exclusion Criteria}

TB patients with a positive $M$. tuberculosis culture were included, DST results, demographic information, and clinical information of the patients were available. Patients without tuberculous mycobacteria were excluded.

\section{Definitions}

\section{Primary Tuberculosis}

TB without a history of previous treatment. ${ }^{17}$

\section{Drug-Resistant Tuberculosis (DR-TB)}

Resistance to any anti-TB drugs, including acquired and primary drug resistance according to whether they had a history of previous treatment. ${ }^{17,18}$

\section{Primary Drug Resistance}

Drug-resistant tuberculosis (DR-TB) without a history of previous treatment. ${ }^{17}$ The elderly new cases of TB refers to a patient $\geq 60$ years of age with primary $\mathrm{TB}{ }^{17}$

\section{Mono-Resistance (MR)}

Resistance to one first-line anti-TB drug only. ${ }^{19}$

\section{Polydrug Resistance (PDR)}

Resistance to more than one first-line anti-TB drug, other than both isoniazid and rifampicin. ${ }^{19}$

\section{Multidrug Resistance (MDR)}

Resistance to at least both isoniazid and rifampicin. ${ }^{19}$

Rifampicin Resistance (RR)

Resistance to rifampicin detected using phenotypic or genotypic. $^{19}$

\section{Statistical Analysis}

Categorical variables, including sex (male or female), drinking (yes/no/unknown), smoking (yes/no/unknown), cavity (yes/no/unknown), patient type (extra-pulmonary TB/pulmonary TB), COPD (yes/no/unknown), diabetes (yes/no/unknown), of primary TB cases were calculated as counts and proportions, respectively. Odds ratios (ORs) and $95 \%$ CIs for the comparisons of specific characteristics between the non-elderly ( $<60$ years) and the elderly ( $\geq 60$ years) were acquired by Pearson chi-square test. $\mathrm{P}<0.05$ was considered to be significant statistically. Chisquare test for trends and linear regression in line charts and stacked bar charts were used to analyze the changes and temporal trend in quantity and proportions of the different resistance patterns over time. All analyses were implemented by using SPSS software (version 20.0).

\section{Ethics Statement}

The study was approved by the Ethics Committee of Shandong Provincial Hospital (SPH), affiliated with Shandong University and the Ethic Committee of Shandong Provincial Chest Hospital (SPCH), China. All patients' data were rendered anonymous before analysis.

\section{Results}

\section{Patients' Characteristics}

Of the 12,661 primary TB case-patients collected from 2004 to 2019 in Shandong, the demographic and clinical information of them were analyzed. Among the primary TB patients, there were 4368 elderly ( $\geq 60$ years) and 8183 non-elderly ( $<60$ years), of which $751(17.19 \%)$ and 1600 $(19.55 \%)$ were drug-resistant TB cases respectively. Among these elderly new cases of $\mathrm{TB}$, there were more males $(87.75 \%$ vs $12.25 \%)$, patients without cavity (64.11\% vs $35.89 \%)$ non-smokers $(70.45 \%$ vs $29.55 \%)$, non-drinkers $(77.77 \%$ vs $22.23 \%)$, pulmonary TB $(99.63 \%$ vs $0.37 \%$ ), patients without COPD (95.33\% vs $4.67 \%)$, patients without diabetes $(92.07 \%$ vs $7.93 \%)$. Similarly, among these elderly new cases of DR TB, there were also more males $(89.35 \%$ vs $10.65 \%)$, patients without cavity (62.86\% vs $37.14 \%)$, non-smokers $(70.09 \%$ vs $29.91 \%)$, non-drinkers $(78.08 \%$ vs $21.92 \%)$, pulmonary TB $(99.73 \%$ vs $0.27 \%$ ), patients without COPD (94.35\% vs $5.65 \%$ ), patients without diabetes $(90.23 \%$ vs $9.41 \%)$. The distribution of sex, smoking, drinking, et al among non-elderly new cases of TB and DR-TB resembled the cases among elderly (Table 1). 
Table I Sociodemographic and Clinical Characteristics of Elderly and Non-Elderly Primary TB Patients, Shandong Province, China, 2004-2019

\begin{tabular}{|c|c|c|c|c|c|c|c|c|}
\hline \multicolumn{2}{|l|}{ Characteristic } & \multicolumn{5}{|c|}{ Age $<60$ Years, No.(\%)n=8183 } & \multirow{2}{*}{\multicolumn{2}{|c|}{ Characteristic }} \\
\hline & & \multirow{2}{*}{$\begin{array}{l}\begin{array}{l}\text { Total } \\
\mathbf{n}=\mathbf{8} \mid 83\end{array} \\
1823(22.28)\end{array}$} & \multirow{2}{*}{$\begin{array}{l}\text { DR-TB } \\
n=1600\end{array}$} & \multirow{2}{*}{$\begin{array}{l}\text { Susceptible } \\
\text { TB } n=6583\end{array}$} & \multirow{2}{*}{$\begin{array}{l}\text { OR(95\% Cl) } \\
\text { No reference }\end{array}$} & \multirow{2}{*}{$\begin{array}{l}\text { P value } \\
\text { No reference }\end{array}$} & & \\
\hline $\begin{array}{l}\text { Sex }(n=8181 / \\
n=1600 / n=6581)\end{array}$ & Female & & & & & & $\begin{array}{l}\operatorname{Sex}(n=4367 / \\
n=75 \mid / n=3616)\end{array}$ & Female \\
\hline & Male & 6358 (77.72) & $1286(80.38)$ & $5072(77.07)$ & $1.218(1.063-1.396)$ & 0.004 & & Male \\
\hline $\begin{array}{l}\text { Cavity }(n=7126 / \\
n=\mid 397 / n=5729)\end{array}$ & No & $4224(59.28)$ & $792(56.69)$ & $3432(59.91)$ & No reference & No reference & $\begin{array}{l}\text { Cavity }(n=3778 / \\
n=657 / n=3 \mid 21)\end{array}$ & No \\
\hline & Yes & $2902(40.72)$ & $605(43.31)$ & $2297(40.09)$ & $1.141(1.014-1.285)$ & 0.028 & & Yes \\
\hline $\begin{array}{l}\text { Smoking }(n=4801 / \\
n=922 / n=3879)\end{array}$ & No & $3722(77.53)$ & $719(77.98)$ & $3003(77.42)$ & No reference & No reference & $\begin{array}{l}\text { Smoking }(n=2680 / \\
n=438 / n=2242)\end{array}$ & No \\
\hline & Yes & $1079(22.47)$ & $203(22.02)$ & $876(22.58)$ & $0.968(0.8|4-1.15|)$ & 0.711 & & Yes \\
\hline $\begin{array}{l}\text { Drinking }(\mathrm{n}=4761 / \\
\mathrm{n}=917 / \mathrm{n}=3844)\end{array}$ & No & $3809(80.00)$ & $752(82.01)$ & $3057(79.53)$ & No reference & No reference & $\begin{array}{l}\text { Drinking }(\mathrm{n}=2667 / \\
\mathrm{n}=438 / \mathrm{n}=1886)\end{array}$ & No \\
\hline & Yes & $952(20.00)$ & $165(17.99)$ & $787(20.47)$ & $0.852(0.708-1.026)$ & 0.092 & & Yes \\
\hline $\begin{array}{l}\text { Type }(n=8 \mid 83 / \\
n=\mid 600 / n=6583)\end{array}$ & Extrapulmonary TB & $23(0.28)$ & $4(0.25)$ & $19(0.29)$ & No reference & No reference & $\begin{array}{l}\text { Type }(n=4368 / \\
n=750 / n=36 \mid 8)\end{array}$ & Extrapulmonary $\mathrm{TB}$ \\
\hline & Pulmonary TB & $8160(99.72)$ & $1596(99.65)$ & $6564(99.7 I)$ & $1.115(0.392-3.400)$ & 0.794 & & Pulmonary TB \\
\hline $\begin{array}{l}\operatorname{COPD}(n=6033 / \\
n=1199 / n=4834)\end{array}$ & No & $6007(99.57)$ & $1196(99.75)$ & $48 I I(99.52)$ & No reference & No reference & $\begin{array}{l}\operatorname{COPD}(\mathrm{n}=3340 / \\
\mathrm{n}=460 / \mathrm{n}=2880)\end{array}$ & No \\
\hline & Yes & $26(0.43)$ & $3(0.25)$ & $23(0.48)$ & $0.350(0.082-1.486)$ & 0.155 & & Yes \\
\hline $\begin{array}{l}\text { Diabetes }(\mathrm{n}=6033 / \\
\mathrm{n}=1 \mid 199 / \mathrm{n}=4834)\end{array}$ & No & $5683(94.20)$ & II 28(94.08) & $4555(94.23)$ & No reference & No reference & $\begin{array}{l}\text { Diabetes }(\mathrm{n}=3340 / \\
\mathrm{n}=563 / \mathrm{n}=2779)\end{array}$ & No \\
\hline & Yes & $350(5.80)$ & $71(5.92)$ & $279(5.77)$ & $1.028(0.786-1.344)$ & 0.842 & & Yes \\
\hline
\end{tabular}

Abbreviations: OR, odds ratio; TB, tuberculosis; DR-TB, drug-resistant tuberculosis.

The elderly new cases of TB were more likely than the non-elderly new cases of TB to be male (OR: 2.045, 95\% CI: $1.850-2.280$ ), to have habits of smoking (OR: 1.447 , 95\% CI: 1.300-1.611) and drinking (OR: 1.144, 95\% CI: 1.019-1.284), and to have COPD (OR: $1.320,95 \% \mathrm{CI}$ : 7.457-17.183) and diabetes (OR: 1.399, 95\% CI: $1.186-$ 1.651). The non-elderly TB case-patients were more likely than the elderly TB case-patients to have cavitary pulmonary disease (OR: $0.815,95 \%$ CI: $0.751-0.884$ ). We also found that the elderly DR-TB case-patients were more likely than the non-elderly DR-TB case patients to be male (OR: 2.048, 95\% CI: 1.575-2.663), to have habits of smoking (OR: $1.511,95 \%$ CI: $1.169-1.954$ ) to have COPD (OR: 23.883, 95\% CI: 7.193-79.305) and diabetes (OR: 1.658, 95\% CI: 1.144-2.402) (Table 1).

\section{Drug-Resistance Patterns}

The number of elderly patients with primary DR-TB was 751, which accounted for $17.19 \%$ among the total primary TB-case-patients collected. Among the 4368 elderly primary TB patients, the highest number and proportion of resistance were SM 469 (10.74\%), followed by INH 446
(10.21\%), RFP 136 (3.11\%), and EMB 56 (1.28\%); the number and proportion of MR-TB including INH, RFP, EMB, SM were 197 (4.51\%), 23 (0.53\%), $13(0.30 \%)$ and $250(5.72 \%)$, respectively. MDR-TB were $100(2.29 \%)$ among the elderly TB patients. There were four main types of primary MDR-TB, MDR1 (INH+RFP), MDR2 (INH+RFP+EMB), MDR3 (INH+RFP+EMB+SM), and MDR4 (INH+RFP+SM), which accounted for $0.80 \%$ (35), $0.05 \%$ (2), $0.60 \%$ (26), and $0.76 \%$ (33) respectively. There were six main types of primary PDR-TB, PDR1 (INH+EMB), PDR2 (INH+SM), PDR3 (RFP+EMB), PDR4 (RFP+SM), PDR5 (INH+EMB+SM), and PDR6 (RFP+EMB+SM), which accounted for $0.11 \%(5), 3.16 \%$ (138), $0.05 \%$ (2), $0.23 \%$ (10), $0.14 \%$ (6) and $0.02 \%$ (1), respectively. The elderly primary $\mathrm{TB}$ cases had a lower rate of DR-TB (17.19\% vs $19.55 \% \mathrm{P}<0.05)$, MDR-TB $(2.29 \%$ vs $3.72 \% \quad \mathrm{P}<0.001)$, any resistance to $\mathrm{RFP}$ (3.11\% vs $5.07 \% \mathrm{P}<0.001)$, resistance to $\mathrm{SM}(10.74 \%$ vs $13.97 \% \quad \mathrm{P}<0.001)$, MR-TB (RFP) $(0.53 \%$ vs $0.88 \%$ $\mathrm{P}<0.05)$, MR-TB (SM) $(5.72 \%$ vs $7.19 \% \mathrm{P}<0.05)$ than the non-elderly. However, the elderly primary TB cases had higher rates of MR-TB (INH) (4.51\% vs 3.50\% 


\begin{tabular}{|c|c|c|c|c|c|c|c|c|}
\hline \multicolumn{5}{|c|}{ Age $\geq 60$ Years, No. (\%)n=4368 } & \multicolumn{2}{|c|}{ Age $\geq 60$ vs $A g e<60$ (total) } & \multicolumn{2}{|c|}{ Age $\geq 60$ vs Age $<60$ (DR-TB) } \\
\hline $\begin{array}{l}\text { Total } \\
n=4368\end{array}$ & $\begin{array}{l}\text { DR-TB } \\
n=75 I\end{array}$ & $\begin{array}{l}\text { Susceptible } \\
\text { TB } n=3617\end{array}$ & OR(95\% Cl) & $P$ value & OR(95\% Cl) & $P$ value & OR(95\% Cl) & $P$ value \\
\hline $535(12.25)$ & $80(10.65)$ & $455(12.58)$ & No reference & $\begin{array}{l}\text { No } \\
\text { reference }\end{array}$ & No reference & $\begin{array}{l}\text { No } \\
\text { reference }\end{array}$ & No reference & $\begin{array}{l}\text { No } \\
\text { reference }\end{array}$ \\
\hline $3832(87.75)$ & 67I (89.35) & 3161 (87.42) & $1.207(0.939-1.553)$ & 0.143 & $2.054(1.850-2.280)$ & $<0.000$ & $2.048(1.575-2.663)$ & $<0.000$ \\
\hline $2422(64.11)$ & $413(62.86)$ & 2009 (64.37) & No reference & $\begin{array}{l}\text { No } \\
\text { reference }\end{array}$ & No reference & $\begin{array}{l}\text { No } \\
\text { referance }\end{array}$ & No reference & $\begin{array}{l}\text { No } \\
\text { reference }\end{array}$ \\
\hline 1356 (35.89) & $244(37.14)$ & $1112(35.63)$ & $1.067(0.897-1.27 \mid)$ & 0.464 & $0.815(0.75 \mid-0.884)$ & $<0.000$ & $0.773(0.639-0.936)$ & 0.008 \\
\hline $1888(70.45)$ & $307(70.09)$ & I58| (70.52) & No reference & $\begin{array}{l}\text { No } \\
\text { reference }\end{array}$ & No reference & $\begin{array}{l}\text { No } \\
\text { reference }\end{array}$ & No reference & $\begin{array}{l}\text { No } \\
\text { reference }\end{array}$ \\
\hline $792(29.55)$ & $131(29.91)$ & 661 (29.48) & $1.021(0.816-1.277)$ & 0.858 & $1.447(1.300-1.61 \mathrm{I})$ & $<0.000$ & $1.511(1.169-1.954)$ & 0.002 \\
\hline 2074 (77.77) & $342(78.08)$ & I732 (9I.83) & No reference & $\begin{array}{l}\text { No } \\
\text { reference }\end{array}$ & No reference & $\begin{array}{l}\text { No } \\
\text { reference }\end{array}$ & No reference & $\begin{array}{l}\text { No } \\
\text { reference }\end{array}$ \\
\hline $593(22.23)$ & $96(21.92)$ & $497(26.35)$ & $0.978(0.764-1.253)$ & 0.861 & $1.144(1.019-1.284)$ & 0.023 & $1.279(0.965-1.696)$ & 0.087 \\
\hline $16(0.37)$ & $2(0.27)$ & $14(0.39)$ & No reference & $\begin{array}{l}\text { No } \\
\text { reference }\end{array}$ & No reference & $\begin{array}{l}\text { No } \\
\text { reference }\end{array}$ & No reference & $\begin{array}{l}\text { No } \\
\text { reference }\end{array}$ \\
\hline 4352 (99.63) & 748(99.73) & 3604 (99.6I) & $1.453(0.330-6.406)$ & 0.622 & $0.767(0.405-1.453)$ & 0.415 & $0.937(0.171-5.129)$ & 0.941 \\
\hline $3184(95.33)$ & $434(94.35)$ & $2750(95.49)$ & No reference & $\begin{array}{l}\text { No } \\
\text { reference }\end{array}$ & No reference & $\begin{array}{l}\text { No } \\
\text { reference }\end{array}$ & No reference & $\begin{array}{l}\text { No } \\
\text { reference }\end{array}$ \\
\hline $156(4.67)$ & $26(5.65)$ & $130(4.51)$ & $1.267(0.822-1.954)$ & 0.284 & $11.320(7.457-17.183)$ & $<0.000$ & $23.883(7.193-79.305)$ & $<0.000$ \\
\hline $3075(92.07)$ & $508(90.23)$ & $2567(53.10)$ & No reference & $\begin{array}{l}\text { No } \\
\text { reference }\end{array}$ & No reference & $\begin{array}{l}\text { No } \\
\text { reference }\end{array}$ & No reference & $\begin{array}{l}\text { No } \\
\text { reference }\end{array}$ \\
\hline $265(7.93)$ & $53(9.4 I)$ & $212(4.39)$ & $1.263(0.921-1.732)$ & 0.147 & $1.399(1.186-1.651)$ & $<0.000$ & $1.658(1.144-2.402)$ & 0.008 \\
\hline
\end{tabular}

$\mathrm{P}<0.05)$ and MR-TB (EMB) $(0.30 \%$ vs $0.11 \% \mathrm{P}<0.05)$ than the non-elderly (Table 2 ).

\section{Trends Over Time}

The elderly DR-TB patients were divided into several different subgroups featured by drug resistance (MR-TB/MDRTB/PDR-TB, INH/RFP/SM/EMB-resistant), sex (male or female), drinking history (yes/no/unknown), smoking history (yes/no/unknown), and cavity (yes/no/unknown). The change of the number and proportions of each subgroups among the total elderly DR-TB patients collected from 2004-2019 are demonstrated in Figure 1A-E and Figure 2. Among the total elderly DR-TB patients, the percentage of male varied from $85.19 \%$ to $89.06 \%$ (R2 $=0.0901$ : $\chi^{2}$ test for trends: $\left.\chi^{2}=3.941, \mathrm{p}<0.05\right)$, the percentage of cavity varied from $7.41 \%$ to $46.88 \%$ (R2 $=0.6069: \chi^{2}$ test for trends: $\chi^{2}=$ 97.545, $\mathrm{p}<0.001$ ), the percentage of RFP-resistance varied from $3.70 \%$ to $21.88 \%\left(\mathrm{R} 2=0.0531: \chi^{2}\right.$ test for trends: $\chi^{2}=$ $5.502, \mathrm{p}<0.05)$, the percentage of SM-resistance varied from $37.04 \%$ to $62.50 \%$ (R2 $=0.1574: \chi^{2}$ test for trends: $\chi^{2}=$ $24.756, p<0.001$ ), the proportion of these subgroups including cavity, RFP-resistance and SM-resistance increased significantly from 2004 to 2019. In addition, the proportion of female, non-cavity and INH-resistance decreased significantly from 2004 to 2019 . The percentage of female varied from $14.81 \%$ to $10.94 \%\left(\mathrm{R} 2=0.0901: \chi^{2}\right.$ test for trends: $\chi^{2}=$ $3.941, \mathrm{p}<0.05)$, the percentage of non-cavity varied from $92.59 \%$ to $32.81 \%\left(\mathrm{R} 2=0.6551: \chi^{2}\right.$ test for trends: $\chi^{2}=$ 208.201, $\mathrm{p}<0.001$ ), INH-resistance varied from $66.67 \%$ to $57.81 \%\left(\mathrm{R} 2=0.2437: \chi^{2}\right.$ test for trends: $\chi^{2}=25.532$, $\mathrm{p}<0.001$ ) (Table 4).

\section{Total and Annual Drug Resistance Rate}

Total and annual drug resistance rates of the elderly in different subgroups are shown in Table 3. The drug resistance rates among these subgroups including MDR-TB, PDR-TB, cavity, RFP-resistant increased by $160.00 \%$, $18.18 \%, 255.00 \%, 231.82 \%$, respectively and changed from $1.10 \%$ to $2.86 \%$, from $2.2 \%$ to $2.60 \%$, from $2.2 \%$ to $7.81 \%$, and from $1.1 \%$ to $3.65 \%$, respectively. However, the drug resistance rates among non-cavity, INH-resistant, EMB-resistant, SM-resistant reduced by $80.09 \%, 51.26 \%$, $52.73 \%$, and $5.19 \%$, respectively and changed from 
Table 2 Primary Drug Resistance Profiles of Mycobacterium Tuberculosis Between Elderly People and Non-Elderly People, Shandong, China, 2004-2019

\begin{tabular}{|c|c|c|c|}
\hline Drug Resistance & Age $<60$ Years, No.(\%) $n=8 \mid 83$ & Age $\geq 60$ Years, No.(\%) $n=4368$ & $P$ value \\
\hline DR-TB (Total) & $1600(19.55)$ & $751(17.19)$ & 0.001 \\
\hline Any resistance to first-line drugs & No reference & No reference & No reference \\
\hline $\mathrm{INH}$ & $873(10.67)$ & $446(10.21)$ & 0.426 \\
\hline RFP & $415(5.07)$ & $136(3.11)$ & $<0.000$ \\
\hline EMB & $|3|(1.60)$ & $56(1.28)$ & 0.16 \\
\hline SM & $1143(13.97)$ & $469(10.74)$ & $<0.000$ \\
\hline MR-TB (Total) & $962(11.76)$ & $488(11.17)$ & 0.330 \\
\hline $\mathrm{INH}$ & $286(3.50)$ & $197(4.5 I)$ & 0.005 \\
\hline RFP & $72(0.88)$ & $23(0.53)$ & 0.031 \\
\hline EMB & $9(0.11)$ & $13(0.30)$ & 0.022 \\
\hline SM & $588(7.19)$ & $250(5.72)$ & 0.002 \\
\hline Others & $7(0.09)$ & $5(0.11)$ & 0.619 \\
\hline MDR-TB (Total) & $304(3.72)$ & $100(2.29)$ & $<0.000$ \\
\hline MDRI:INH+RFP & $55(0.67)$ & $35(0.80)$ & 0.415 \\
\hline MDR2:INH+RFP+EMB & II (0.13) & $2(0.05)$ & 0.161 \\
\hline MDR3:INH+RFP+EMB+SM & $69(0.84)$ & $26(0.60)$ & 0.127 \\
\hline MDR4:INH+RFP+SM & $153(1.87)$ & $33(0.76)$ & $<0.000$ \\
\hline Others & $16(0.20)$ & $4(0.09)$ & 0.174 \\
\hline PDR-TB(Total) & $343(4.19)$ & $163(3.73)$ & 0.212 \\
\hline PDRI:INH+EMB & $9(0.11)$ & $5(0.11)$ & 0.943 \\
\hline PDR2:INH+SM & $272(3.32)$ & $138(3.16)$ & 0.621 \\
\hline PDR3:INH+EMB+SM & $I I(0.13)$ & $6(0.14)$ & 0.966 \\
\hline PDR4:RFP+EMB & $5(0.06)$ & $2(0.05)$ & 0.729 \\
\hline PDR5:RFP+SM & $36(0.44)$ & $10(0.23)$ & 0.067 \\
\hline PDR6:RFP+EMB+SM & $4(0.05)$ & $\mathrm{I}(0.02)$ & 0.497 \\
\hline Others & $6(0.07)$ & $\mathrm{I}(0.02)$ & 0.254 \\
\hline
\end{tabular}

Abbreviations: EMB, ethambutol; INH, isoniazid; NA, not applicable; RFP, rifampin; SM, streptomycin; TB, tuberculosis; DR-TB, drug-resistant tuberculosis; MR-TB, monoresistant tuberculosis; MDR-TB, multi-resistant tuberculosis; PDR-TB, polydrug resistant tuberculosis.

$27.47 \%$ to $5.47 \%$, from $19.78 \%$ to $9.64 \%$, from $2.2 \%$ to $1.04 \%$, and from $10.99 \%$ to $10.42 \%$ respectively (Table 3 ).

\section{Discussion}

This retrospective cohort study collected 12,661 primary TB case-patients in Shandong, the second largest province in China, from 2004 to 2019, to evaluate the epidemiological characteristics and trend among the elderly DR-TB. We made some findings in this study: 1) Among the elderly, the proportions in these subgroups including MDR-TB, PDR-TB, RFP-resistance and cavitary DR-TB increased significantly; 2) Among the total elderly DR-TB patients, the percentage of male (from $85.19 \%$ to $89.06 \%$ ), cavity (from 7.41\% to 46.88\%), RFP-resistance (from $3.70 \%$ to $21.88 \%$ ), SM-resistance (from $37.04 \%$ to $62.50 \%$ ) increased.

According to the WHO report, TB prevalence increased with age in Asia and some African countries (e.g. Ghana, Malawi, Rwanda, the United Republic of Tanzania and Zimbabwe), the peak of prevalence in some Africa countries (e.g. Ethiopia, Gambia, Namibia, Nigeria, Sudan, Uganda and Zambia) were among those people aged $35-54$ years. ${ }^{19}$ It was estimated that the elderly population in China will rise to 400 million by $2030 .^{2}$ The prevalence of tuberculosis in the population aged 65 years and older was more than twice as high as that in younger adults. ${ }^{20}$ Elderly patients have been repeatedly reported to have a lower treatment completion rate and are less health aware than younger patients, which means the diagnosis and treatment in elderly TB is very difficult for us. ${ }^{21,22}$ So TB in the elderly should be appreciated. Meanwhile we found that the elderly ( $\geq 60$ years) primary TB patients accounted for about one third (4368/ $12,661,34.50 \%$ ) of the total new TB cases.

Besides this we found that the elderly with TB were more likely to be male, to have habits of smoking or 
A

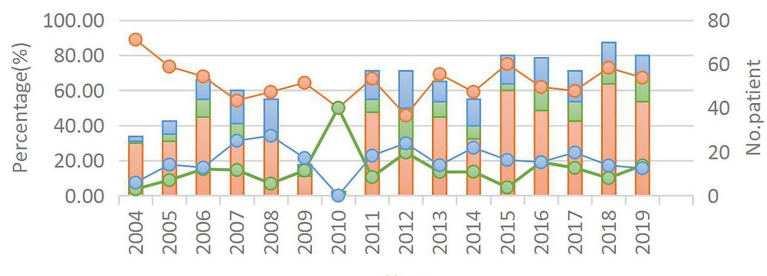

Year

$\square$ MR-TB (no.) $\square$ MDR-TB (no.) $\square$ PDR-TB (no.)

$\multimap-M R-T B(\%) \quad \longrightarrow$ MDR-TB (\%) —-PDR-TB (\%)

C

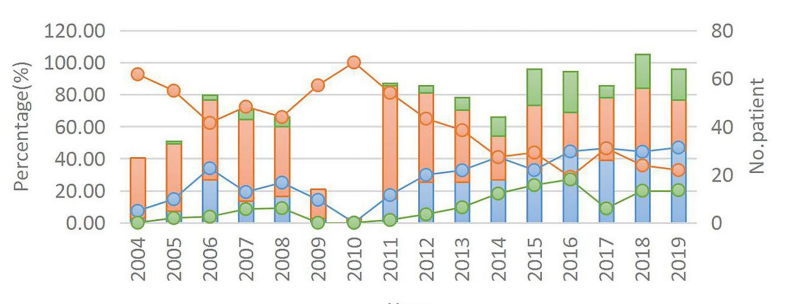

Year

$\square$ Cavity (no.) $\square$ Non-cavity (no.) $\square$ Unknown (no.)

E

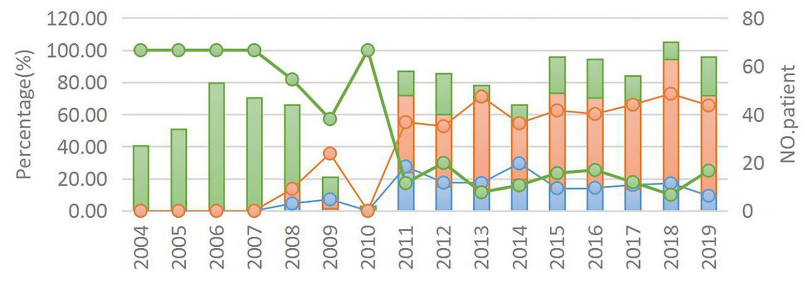

Year
B

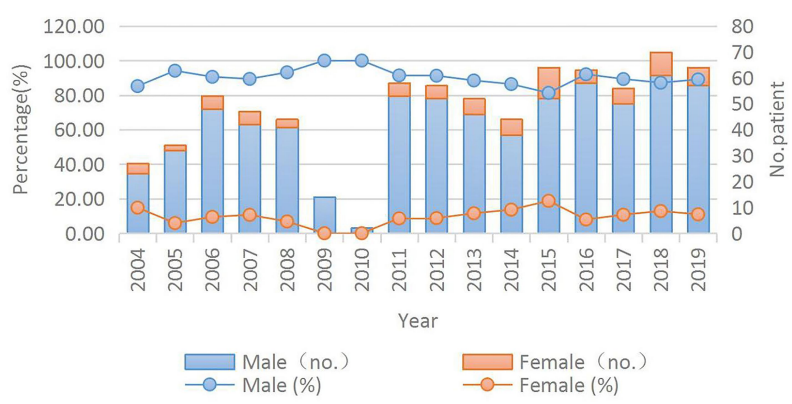

D

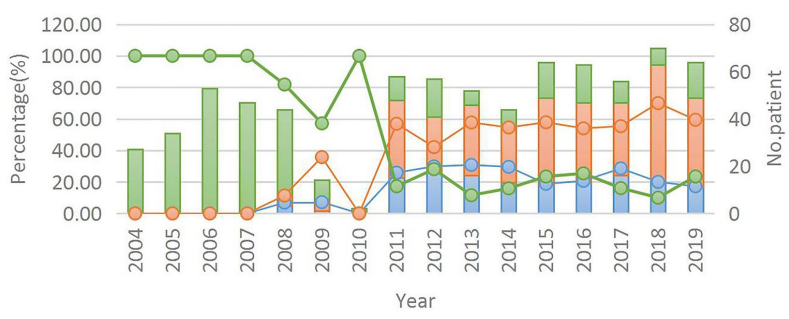

$\square$ Smoking (no.) $\square$ Non-smoking (no.) $\square$ Unknown (no.) -0-Smoking (\%) - $\quad$ - Non-smoking (\%) —- Unknown (\%)

$\square$ Drinking (no.) $\square$ Non-drinking (no.) $\square$ Unknown (no.)

Figure I Trends for the quantity and proportions of different subgroups among the total elderly primary DR-TB cases, Shandong, China, 2004-20I9*. (A) Trends for MRTB, MDR-TB, PDR-TB among the elderly with primary TB; (B) Trends for the elderly primary DR-TB cases of different sex (male or female); (C) Trends for primary DR-TB cases with or without cavity; (D) Trends for primary DR-TB cases with or without smoking history; (E) Trends for primary DR-TB cases with or without drinking history; The proportions of each subgroups were calculated as follows: (the quantity of each subgroups/the quantity of the total elderly primary DR-TB subgroups in the same year) $\times 100 \%$; The $\chi^{2}$ and linear regression results are shown in Table 4 .

Abbreviations: TB, tuberculosis; DR-TB, drug-resistant tuberculosis; MR-TB, mono-resistant tuberculosis; MDR-TB, multi-resistant tuberculosis; PDR-TB, polydrug resistant tuberculosis; EMB, ethambutol; INH, isoniazid; RFP, rifampin; SM, streptomycin.

drinking, and to develop complications such as COPD or diabetes than the non-elderly. However, we found that there was no statistical significance between elderly DR-TB cases and elderly susceptible TB cases in these factors. Interestingly, we found that elderly DR-TB cases are more likely to be male and to like smoking than non-elderly DR-TB cases. Some surveys showed a systematically higher burden of TB disease among men, with M:F (Male/Female) ratios ranging from 1.2 (in Ethiopia) to 4.9 (in Vietnam). The M:F ratios were generally higher in Asia than in Africa, that was in the range of $2-4 .^{2}$ In 2017, TB cases in all EU/EAA (European Union/East Asian Area) member states tended to be male. In Poland, the proportion of men in the elderly group with $\mathrm{TB}$ was much higher than women. ${ }^{23}$ This phenomenon may be associated with social behavior factors and biological sex-related factors, such as sex steroid hormones, the genetic makeup of the sex chromosomes, and sex-specific metabolic features. ${ }^{24}$ To avoid or decrease risk factors among the population is also very important in the control of tuberculosis. Diabetes, alcohol use, and smoking all 


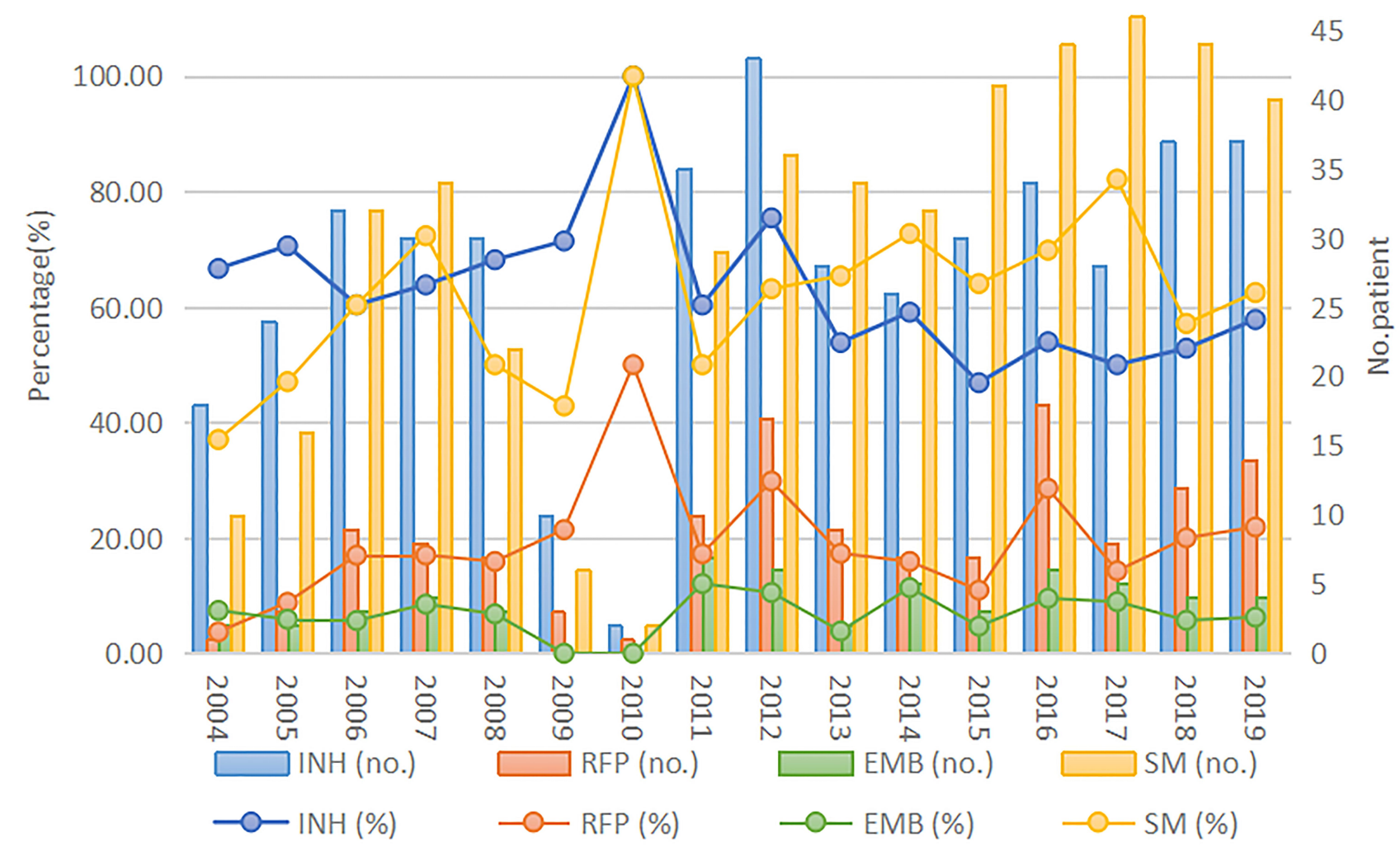

Figure 2 Overall first-line drug resistance for INH, RIF, EMB, and SM among the elderly cases of primary drug-resistant tuberculosis in Shandong, China, 2004-20I9. The proportions of INH-, RIF-, EMB-, and SM-resistance were calculated as follows: (the quantity of each subgroups/the quantity of total the elderly primary DR-TB subgroups in the same year) $\times 100 \%$; The $\chi^{2}$ and linear regression results are shown in Table 4 .

Abbreviations: EMB, ethambutol; INH, isoniazid; RFP, rifampin; SM, streptomycin.

accounted for about a quarter of tuberculosis deaths and DALYs (disability-adjusted life years) around the world in 2015. ${ }^{7}$ These factors may increase the risk of TB by impairing the immune system of humans. ${ }^{25-27}$ Smoking made it easy to develop TB which is related to ciliary dysfunction, a reduced immune response, and to defects in the immune response of macrophages, with or without a decrease in the CD4 count. $^{28}$ Some evidence suggested that drinking was linked to tuberculosis treatment compliance and may lead to subsequent acquired drug resistance. Besides it might be related to the sequelae of alcohol use disorders (AUD). ${ }^{25,29}$ Diabetes leads to an increased susceptibility to tuberculosis through some mechanisms, including hyperglycemia and cellular insulinopenia, which have indirect effects on macrophage and lymphocyte function. ${ }^{30}$ The study pointed out that the impaired innate defence mechanisms in the airways of COPD patients might increase the risk of $\mathrm{TB}$ infection or the possibility of developing active TB from latent $\mathrm{TB}$ infection (LTBI). ${ }^{31}$
Furthermore, the study suggested that the immune system would be weakened while susceptibility to chronic disease would increase with aging. ${ }^{32}$ Taking some measures to prevent these risk factors may have a cascade effect on the control of TB and DR-TB in the elderly.

The results of the National Prevalence Survey showed China has $5.7 \%$ of newly diagnosed and $25.6 \%$ of previously treated cases of MDR-TB. ${ }^{33}$ In addition, the DR-TB and MDR-TB accounted for $18.10 \%$ and $2.89 \%$ respectively of the elderly with TB in our study. Meanwhile, we found that the annual drug resistant rate of MDR-TB, PDR-TB, RFPresistance and cavitary DR-TB increased significantly in our study. These might be related to lower treatment completion rate and absence of health awareness and inadequate treatment and so on. ${ }^{21,22}$ Increments of MDR-TB were also be found in previous studies in Beijing (from 2005 to 2008), ${ }^{34}$ in Korea, ${ }^{35}$ in Taiwan, etc. ${ }^{36}$ The drug resistant rate of MDRTB decreased in Zhejiang, China very slowly. ${ }^{37}$ China has the world's largest number of patients with MDR-TB. Inadequate treatment in both the public health system and 


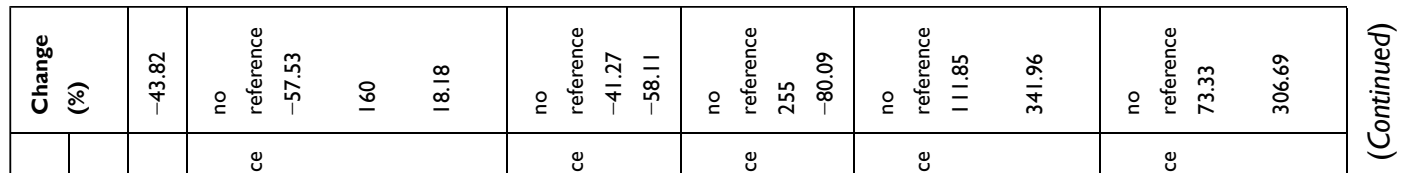

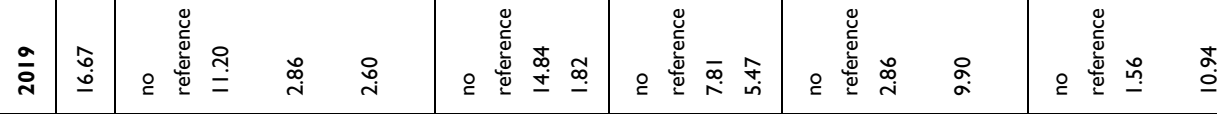

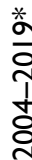

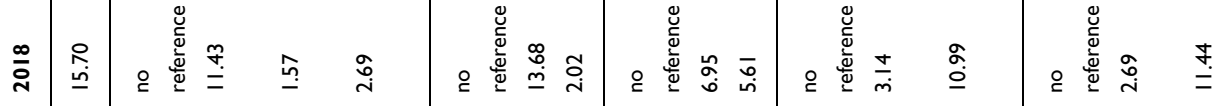

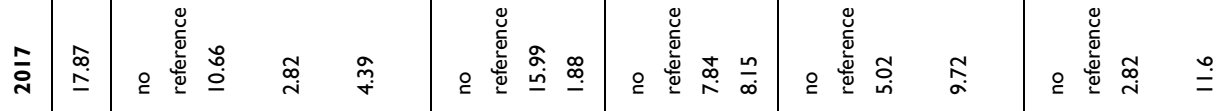

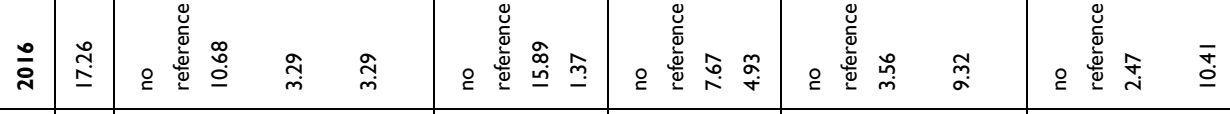

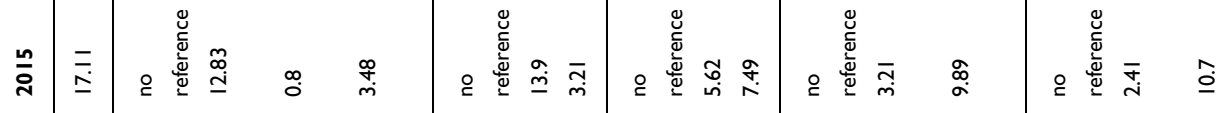

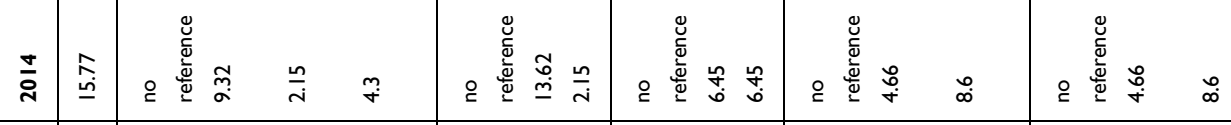

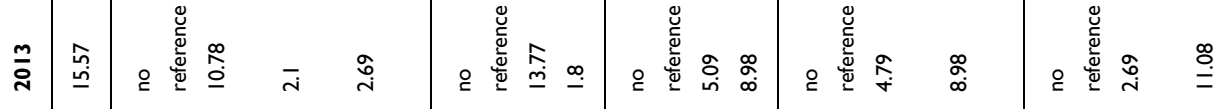

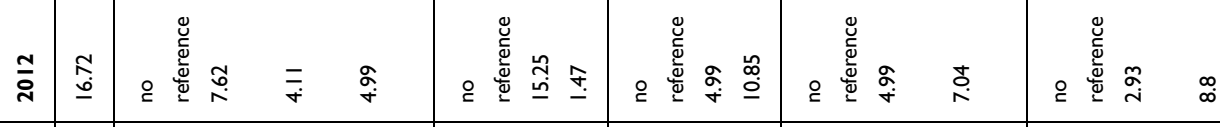

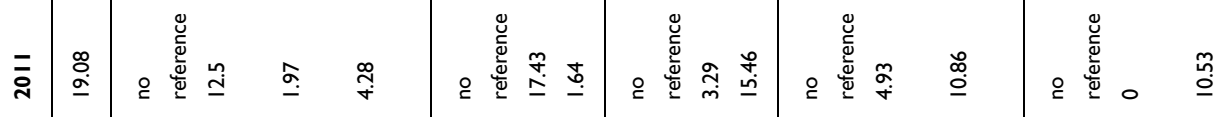
政

 完

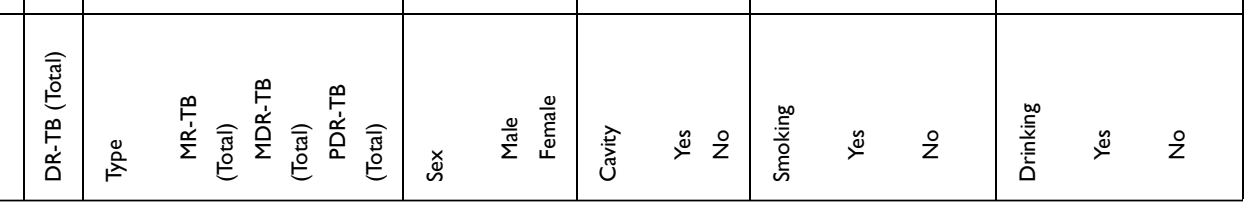




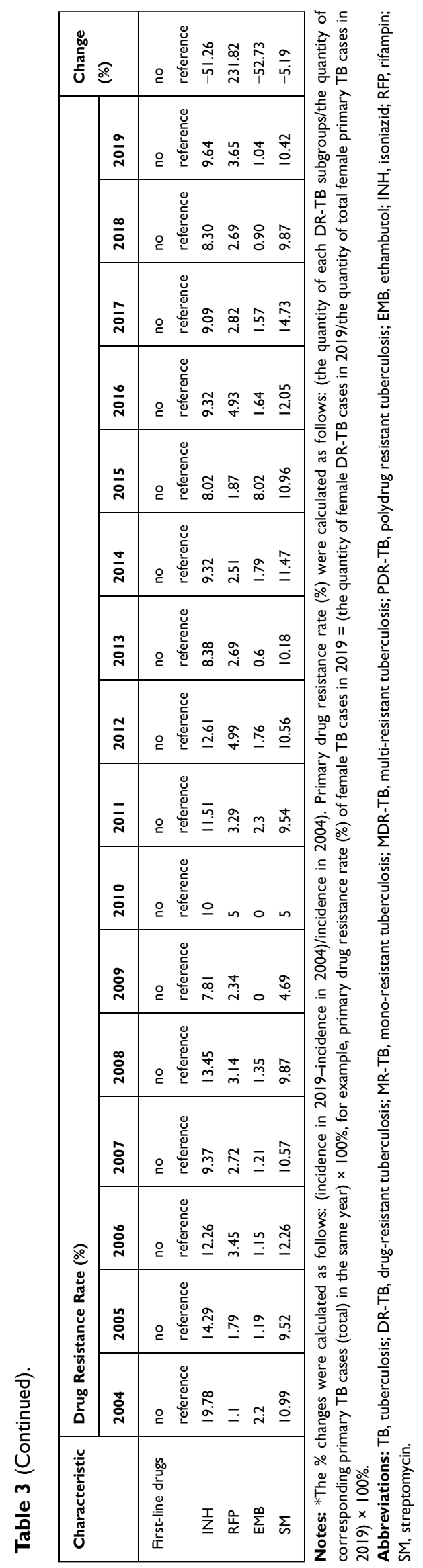

the hospital system may lead to more MDR-TB infection. The treatment of MDR-TB/RR-TB is difficult, complicated and costly. ${ }^{9,38}$ All of these alarm us that the MDR-TB plays a key role in the burden of DR-TB disease. We found that the elderly had a higher resistance rate of MRTB (INH or EMB) and a lower resistance rate to any one of $\mathrm{INH}$, RFP, EMB, and SM compared to that in the nonelderly. These phenomenon could also be found in Taiwan, ${ }^{39-42}$ and in United Kindom. ${ }^{43}$ And we also found that the drug resistant patterns changed into male, cavitary TB, RFP-resistance and SM-resistance among the elderly. Although we found that the drug resistant rates of different subgroups (MR-TB, male, cavity, smoking, drinking, INHresistance, RFP-resistance, EMB-resistance, SM-resistance) declined and became very low during 2008-2010. We speculated it may be related to the policies China carried out in China in recent years, these policies may have a delayed effect. ${ }^{4-46}$ Some previous studies suggested that the cavity of tuberculosis could lead to an increased possibility of DRTB during treatment. ${ }^{47}$ The prevalence of DR-TB was significantly higher among males in some studies. ${ }^{48}$ It had been noticed that cavities were more common in DR-TB cases than in susceptible TB cases, and this phenomenon may be caused by limited drug penetration into cavities, the suitable environment provided by cavities for bacilli, patients' immunity, etc. ${ }^{48-52}$ These may be the reasons that the DR-TB pattern changed. The change of the DR-TB pattern will bring us a huge challenge to control the DR-TB in the elderly.

There were several advantages in our study. Firstly, the study was conducted in Shandong province, the second largest province in China, from 2004 to 2019. All DST data of first-line anti-TB drugs (INH, RFP, EMB, SM) were involved in our study. The time span of our research is large and the scope is wide, so that our findings are more likely to be generalized throughout the country. Secondly, we screened out the elderly with TB, and divided the elderly with TB and DR-TB into different subgroups according to sex, smoking history, drinking history, cavity, COPD, diabetes and so on.

Our study also had some limitations. Firstly, DST were not regularly executed among all TB patients, TB surveillance stations had differences in screen density and medical conditions, which might induce selection bias in our data. Secondly, there were some unavoidable bias induced by different technical levels and experimental conditions in TB surveillance. Lastly, the statistical data on smoking and drinking from 2004 to 2007 is missing in our study, thus we could not analyze the subgroups among the elderly with DR-TB including smoking, drinking, etc very well. 
Table 4 Changes in Proportions of Different Primary Drug-Resistant Mycobacterium Tuberculosis Subgroups Among the Elderly, Shandong Province, China, 2004-2019

\begin{tabular}{|l|l|l|l|l|l|}
\hline Subgroups & $\chi^{2}$ & P value & R2 & X-Coefficient & SE \\
\hline MR-TB (\%) & 1.793 & 0.181 & 0.0241 & -0.003437 & 0.67614 \\
MDR-TB (\%) & 1.179 & 0.278 & 0.0098 & 0.002233 & 0.1324 \\
PDR-TB (\%) & 0.486 & 0.486 & 0.0057 & 0.001366 & 0.18946 \\
Male (\%) & 3.941 & 0.047 & 0.0901 & -0.00307 & 0.9315 \\
Female (\%) & 3.941 & 0.047 & 0.0901 & 0.00307 & 0.0685 \\
Cavity (\%) & 97.545 & $<0.000$ & 0.6069 & 0.024115 & 0.076289 \\
Non-cavity (\%) & 208.201 & $<0.000$ & 0.6551 & -0.038137 & 0.94479 \\
Smoking (\%) & 101.315 & $<0.000$ & 0.5459 & 0.019259 & -0.016761 \\
Non-smoking (\%) & 390.327 & $<0.000$ & 0.7902 & 0.051071 & -0.087337 \\
Drinking (\%) & 58.02 & $<0.000$ & 0.4013 & 0.013079 & -0.002038 \\
Non-drinking (\%) & 461.412 & $<0.000$ & 0.8027 & 0.056592 & -0.099645 \\
INH (\%) & 25.532 & $<0.000$ & 0.2437 & -0.013242 & 0.74462 \\
RFP (\%) & 5.502 & 0.019 & 0.0531 & 0.005063 & 0.1506 \\
EMB (\%) & 0.722 & 0.395 & 0.0236 & 0.001139 & 0.057315 \\
SM (\%) & 24.756 & $<0.000$ & 0.1574 & 0.013045 & 0.51201 \\
\hline
\end{tabular}

Notes: INH (\%), RFP (\%), EMB (\%), and SM (\%) refer to the proportion of primary INH/RFP/EMB/SM resistant TB among total primary DR TB cases, respectively. Abbreviations: MR-TB, mono-resistant tuberculosis; MDR-TB, multi-resistant tuberculosis; PDR-TB, polydrug resistant tuberculosis; EMB, ethambutol; INH, isoniazid; RIF, rifampin; SM, streptomycin; TB, tuberculosis.

\section{Conclusion}

The study presented the epidemiological characteristics and trend of primary DR-TB among the elderly in Shandong, China, from 2004-2019. We found that the proportion of MDR-TB, PDR-TB and RFP-resistance and the rate of cavitary DR-TB among the elderly increased significantly, drug resistance patterns among the elderly modified from female, non-cavity and INH-resistance to male, cavity and RFP, SMresistance. The elderly new cases of TB were more common in males, having a history of smoking or drinking, and having COPD or diabetes. Similarly, the elderly new cases of DRTB were more common in males, having history of smoking, and having COPD or diabetes. We should pay more attention to these subgroups including male, smoking, drinking, COPD and diabetes to prevent DR-TB in the elderly. Besides, support of the government, improvement of medical facilities, and enhancement of public awareness are also very important. Older adults play very important roles in modern society in China, understanding the epidemiological characteristics and trends of primary DR-TB among the elderly will make the control of DR-TB much easier.

\section{Abbreviations}

TB, tuberculosis; DR-TB, drug-resistant tuberculosis; WHO, World Health Organization; COPD, chronic obstructive pulmonary disease; SDG, Sustainable Development Goal; RR$\mathrm{TB}$, rifampin-resistant tuberculosis; MR-TB, mono-resistant tuberculosis; MDR-TB, multi-resistant tuberculosis; PDRTB, polydrug resistant tuberculosis; XDR-TB, extensive drug resistant TB; ORs, odds ratios; CI, confidence interval; EMB, ethambutol; INH, isoniazid; RFP, rifampin; SM, streptomycin; M, male; F, female; EU, European Union; EAA, East Asian Area; DALYs, disability-adjusted life years; AUD, alcohol use disorder.

\section{Data Sharing Statement}

Data can be made available through contact with the corresponding author.

\section{Ethics Approval and Consent to Participate}

This study involved 12,661 new TB cases with drug susceptibility data and epidemiological information. Two province-level hospitals, 13 municipal-level and 21 county-level local health departments were responsible for the surveillance of DR-TB in Shandong from 2004 to 2019. Before our team obtained the data and conducted statistical analysis, any personal identifiers of the TB patients had been removed by the monitoring stations. So patient informed consents were not required, and this study was conducted in accordance with the Declaration of Helsinki. The protocols applied in this study were approved by the Ethics Committee of Shandong Provincial Hospital, affiliated with Shandong University 
(SPH) and the Ethics Committee of Shandong Provincial Chest Hospital (SPCH), China.

\section{Acknowledgments}

We are grateful to get drug susceptibility data, sociodemographic and clinical data from Shandong Provincial Hospital, Shandong Provincial Chest Hospital, 13 municipal-level and 21 county-level local health departments.

\section{Author Contributions}

(A) C.L. conceived and designed the study. H.C.L. and Q. Q.A. directed its implementation including the data analysis and writing of the paper. Q.Q.A. analyzed the data; Y.L., Q.Y.Z., J.Y.L., T.T.X., S.J.L., S.Q.L., N.N. T., Y.F.L. and C.B.Y. contributed materials/analytic tools; Q.Q.A., W.M.S. and H.C.L. wrote and revised the manuscript. All authors contributed to data analysis, drafting or revising the article, have agreed on the journal to which the article will be submitted, gave final approval of the version to be published, and agree to be accountable for all aspects of the work.

\section{Funding}

This work was supported by the Department of Science \& Technology of Shandong Province (CN) (No. 2007GG30002033; No. 2017GSF218052) and Jinan Science and Technology Bureau (CN) (No. 201704100).

\section{Disclosure}

The authors declare that they have no competing interests.

\section{References}

1. World Health Organization. Global Tuberculosis Report 2019. Geneva: World Health Organization; 2019. Available from: http:// www.who.int/tb/publications/global_report/en. Accessed October 19, 2020.

2. World Health Organization. Global Tuberculosis Report 2018. Geneva: WorldHealth Organization; 2018. Available from: http:// www.who.int/tb/publications/global_report/en. Accessed October 19, 2020.

3. GBD Tuberculosis collaborators. Global, regional, and national burden of tuberculosis, 1990-2016: results from the global burden of diseases, injuries, and risk factors 2016 Study. Lancet Infect Dis. 2018;18:1329-1349. doi:10.1002/hed.26378

4. Dheda K, Gumbo T, Maartens G; GBD Tuberculosis collaborators. The epidemiology, pathogenesis, transmission, diagnosis, and management of multidrug-resistant, extensively drug-resistant, and incurable tuberculosis. Lancet Respir Med. 2017;5(4):291-360. doi:10. 1016/S2213-2600(17)30079-6

5. United Nations Development Program. china human development report 2013. Available from https://www.cn.undp.org/content/china/ en/home/library/human_development/china-national-humandevelopment-report-2013.html. Accessed October 19, 2020.
6. Negin J, Abimbola S, Marais BJ. Tuberculosis among older adults time to take notice. Int J Infect Dis. 2015;32:135-137. doi:10.1016/j. ijid.2014.11.018

7. Kyu HH, Maddison ER, Henry NJ; GBD Tuberculosis Collaborators. The global burden of tuberculosis: results from the Global Burden of Disease Study 2015. Lancet Infect Dis. 2018;18(3):261-284. doi:10.1016/S1473-3099(17)30703-X

8. Pradipta IS, Forsman LD, Bruchfeld J, Hak E, Alffenaar J-W. Risk factors of multidrug-resistant tuberculosis: a global systematic review and meta-analysis. $J$ Infect. 2018. doi:10.1016/j.jinf

9. Seung KJ, Keshavjee S, Rich ML. Multidrug-resistant tuberculosis and extensively drug-resistant tuberculosis. Cold Spring Harb Perspect Med. 2015;5:a017863. doi:10.1101/cshperspect. a017863

10. Chaulet P, Boulahbal F, Grosset J. Surveillance of drug resistance for tuberculosis control: why and how? Tuber Lung Dis. 1995;76:487-492. doi:10.1016/0962-8479(95)90523-5

11. Cheng J, Sun Y-N, Zhang C-Y, et al. Incidence and risk factors of tuberculosis among the elderly population in China: a prospective cohort study. Infect Dis Poverty. 2020;9(1):13. doi:10.1186/s40249019-0614-9

12. Xin H, Zhang H, Liu J, et al. Mycobacterium tuberculosis infection among the elderly in 20486 rural residents aged 50-70 years in Zhongmu County, China. Clin Microbiol Infect. 2019;25 (9):1120-1126. doi:10.1016/j.cmi.2019.01.021

13. Zhang C-Y, Zhao F, Xia -Y-Y, et al. Prevalence and risk factors of active pulmonary tuberculosis among elderly people in China: a population based cross-sectional study. Infect Dis Poverty. 2019;8 (1):7. doi:10.1186/s40249-019-0515-y

14. Jing $\mathrm{H}$, Wang $\mathrm{H}$, Wang $\mathrm{Y}$, et al. Prevalence of nontuberculous mycobacteria infection, China, 2004-2009. Emerging Infect Dis. 2012;18(3):527-528. doi:10.3201/eid1803.110175

15. Zhou Y, van den Hof S, Wang S, et al. Association between genotype and drug resistance profiles of Mycobacterium tuberculosis strains circulating in China in a national drug resistance survey. PLoS One. 2017;12(3). doi:10.1371/journal.pone.0174197

16. World Health Organization. Guidelines for Surveillance of Drug Resistance in Tuberculosis. 5th ed. Geneva: TheOrganization; 2015. https://www.who.int/tb/publications/2015/drs_guidelines/en. Accessed October 19, 2020.

17. Van RA, Warren R, Richardson $M$, et al. Classification of drug-resistant tuberculosis in an epidemic area. Lancet. 2000;356 (9223):22-25. doi:10.1016/s0140-6736(00)02429-6

18. Chiang C-Y, Schaaf HS. Management of drug-resistant tuberculosis. Int J Tuberc Lung Dis. 2010;14(6):672-682. doi:10.1016/S0140$6736(19) 31882-3$

19. World Health Organization. Definitions and Reporting Framework for Tuberculosis-2013 Revision. Vol. 2. Geneva: World Health Organization; 2013b. https://www.who.int/tb/publications/defini tions/en/. Accessed October 19, 2020.

20. Abuaku B, Tan H, Li X, Chen M, Huang X. Treatment default and death among tuberculosis patients in Hunan, China. Scand J Infect Dis. 2010;42(4):281-287. doi:10.3109/00365540903493723

21. Cantalice Filho JP, Boia MN, Sant Anna CC. Analysis of the treatment of pulmonary tuberculosis in elderly patients at a university hospital in Rio de Janeiro, Brazil. J Bras Pneumol. 2007;33. 691-698. doi: 10.1590/s1806-37132007000600013

22. Bele S, Jiang W, Lu H 1, et al. Population aging and migrant workers: bottlenecks in tuberculosis control in Rural China. PLoS One. 2014;9 (2):e88290. doi:10.1371/journal.pone. 0088290

23. Koseła MK. Tuberculosis in poland in 2017*. Przegl Epidemiol. 2019;73(2):211-226. doi:10.32394/pe.73.20

24. Neyrolles O, Quintana-Murci L. Sexual inequality in tuberculosis. PLoS Med. 2009;6(12):e1000199. doi:10.1371/journal.pmed.1000199

25. Simet SM, Joseph H. Sisson. Alcohol's effects on lung health and immunity. Alcohol Health Res World. 2015;37(2):199-208. 
26. Seonadh MO, Leary MM, Chew WM, et al. Cigarette smoking impairs human pulmonary immunity to Mycobacterium tuberculosis. Am J Respir Crit Care Med. 2014;190(12). doi:10.1164/rccm.201407-1385OC

27. Peleg AY, Thilak Weerarathna JS, McCarthy TM, Davis E. Common infections in diabetes: pathogenesis, management and relationship to glycaemic control. Diabetes Metab Res Rev. 2007;23(1):3-13. doi:10.1002/dmrr.682

28. van Zyl Smit RN, Pai M, Yew WW, et al. Global lung health: the colliding epidemics of tuberculosis, tobacco smoking, HIV and COPD. Eur Respir J. 2010;35(1):27-33. doi:10.1183/09031936.00072909

29. Silva DR, Muñoz-Torrico M, Duarte R, et al. Risk factors for tuberculosis: diabetes, smoking, alcohol use, and the use of other drugs. J Bras Pneumol. 2018;44(2):145-152. doi:10.1590/s1806-37562017000000443

30. Workneh MH, Bjune GA, Yimer SA. Prevalence and associated factors of tuberculosis and diabetes mellitus comorbidity: a systematic review. PLoS One. 2017;12(4):e0175925. doi:10.1371/journal.pone.0175925

31. Inghammar M, Löfdahl CG, Winqvist N, Ljungberg B, Egesten A, Engström G. Impaired pulmonary function and the risk of tuberculosis: a population-based cohort study. Eur Respir J. 2011;37(5):May doi:10.1183/09031936.00091110

32. Müller L, PawelecG. Aging and immunity - impact of behavioral intervention. Brain Behav Immun. 2014;39:8-22. doi:10.1016/j.bbi.2013. 11.015

33. Zhao Y, Xu S, Wang L, et al. National survey of drug resistant tuberculosis in China. $N$ Engl $J$ Med. 2012;366:2161-2170. doi:10.1056/NEJMoa1108789

34. Liao S, Cai C, Huo F-M, et al. Trends in drug-resistant tuberculosis in China: data from a clinical tuberculosis centre. Int J Tuberc Lung Dis. 2017;21(9):990-995. doi:10.5588/ijtld.17.0086

35. Park Y-S, Sung-Jin Hong MD, Boo Y-K Ph.D, et al. The National Status of tuberculosis using nationwide medical records survey of patients with tuberculosis in Korea. Tuberc Respir Dis (Seoul). 2012;73(1):48-55. doi:10.4046/trd.2012.73.1.48

36. Chuang P-H, Wu M-H, Fan S-Y, Lin K-Y, Jou R, Sola C. Population-based drug resistance surveillance of multidrug-resistant tuberculosis in Taiwan, 2007-2014. PLoS One. 2016;11(11):e0165222. doi:10.1371/journal. pone. 0165222

37. Wua B, Zhangb L, Liua Z, et al. Drug-resistant tuberculosis in Zhejiang Province, China: an updated analysis of time trends, 1999-2013. Glob Health Action. 2017;10(1):1293925. doi:10.1080/ 16549716.2017.1293925

38. Prasad R, Gupta N, Banka A. Multidrug-resistant tuberculosis/rifampicin-resistant tuberculosis: principles of management. Lung India. 2018;35(1):78-81. doi:10.4103/lungindia.lungindia_98_17

39. Su WJ, Feng JY, Huang CC, Perng RP. Increasing drug resistance of Mycobacterium tuberculosis isolates in a medical center in northern Taiwan. J Formos Med Assoc. 2008;107:259-264. doi:10.1016/S09296646(08)60145-X
40. Liaw YS, Hsueh PR, Yu CJ, Wang SK, Yang PC, Luh KT. Drug resistance pattern of Mycobacterium tuberculosis in a university hospital in Taiwan, 1998-2002. J Formos Med Assoc. 2004;103:671-6779.

41. Yu MC, Suo J, Chiang CY, Bai KJ, Lin TP, Luh KT. Initial drug resistance of Mycobacterium tuberculosis in Taiwan. J Formos Med Assoc. 1997;96:890-894.

42. Liu W-L, Lai -C-C, Tan C-K, et al. Declining drug resistance of Mycobacterium tuberculosis isolates from elderly patients in Taiwan, 2000-2008. Eur J Clin Microbiol Infect Dis. 2010;29(11):1413-1416. doi:10.1007/s10096-010-1019-7

43. Djuretic T, Herbert J, Drobniewski F, et al. Antibiotic resistant tuberculosis in the United Kingdom: 1993-1999. Thorax. 2002;57:477-482. doi:10.1136/thorax.57.6.477

44. Jia X, Chen J, Zhang S, Dai B, Long Q, Tang S. Implementing a "free" tuberculosis (TB) care policy under the integrated model in Jiangsu, China: practices and costs in the real world. Infect Dis Poverty. 2016;5(1):1. doi:10.1186/s40249-016-0099-8

45. Wang L, Zhang H, Ruan Y, et al. Tuberculosis prevalence in China, 1990-2010; a longitudinal analysis of national survey data. Lancet. 2014;383(9934):2057-2064. doi:10.1016/S0140-6736(13)62639-2

46. Wang L Prof, Liu J MD, Chin DP Dr. Progress in tuberculosis control and the evolving public-health system in China. Lancet. 2007;369 (9562):691-696. doi:10.1016/S0140-6736(07)60316-X

47. Kempker RR, Rabin AS, Nikolaishvili K, et al. Additional drug resistance in mycobacterium tuberculosis isolates from resected cavities among patients with multidrug-resistant or extensively drug-resistant pulmonary tuberculosis. Clin Infect Dis. 2012;54(6):e51-e54. doi:10.1093/cid/cir904

48. Adejumo OA, Olusola-Faleye B, Adepoju V, et al. Prevalence of rifampicin resistant tuberculosis and associated factors among presumptive tuberculosis patients in a secondary referral hospital in Lagos Nigeria. Afri Health Sci. 2018;18(3):472-478. doi:10.4314/ahs.v18i3.2

49. Li D, He W, Chen B, Lv P. Primary multidrug-resistant tuberculosis versus drug sensitive tuberculosis in non-HIV-infected patients: comparisons of CT findings. PLoS One. 2017;12(6):e0176354. doi:10.1371/journal. pone. 0176354

50. Dheda K, Lenders L, Magombedze G, et al. Drug-penetration gradients associated with acquired drug resistance in patients with tuberculosis. Am J Respir Crit Care Med. 2018;198(9):1208-1219. doi:10.1164/rccm.201711-2333OC

51. Dartois V, Barry CE. Clinical pharmacology and lesion penetrating properties of second- and third-line antituberculous agents used in the management of multidrug-resistant (MDR) and extensively-drug resistant (XDR) tuberculosis. Curr Clin Pharmacol. 2010;5 (2):96-114. doi:10.2174/157488410791110797

52. Kaplan G, Post FA, Moreira AL, et al. Mycobacterium tuberculosis growth at the cavity surface: a microenvironment with failed immunity. Infect Immun. 2003;71(12):7099-7108. doi:10.1128/iai.71.12.70997108.2003
Infection and Drug Resistance

\section{Publish your work in this journal}

Infection and Drug Resistance is an international, peer-reviewed openaccess journal that focuses on the optimal treatment of infection (bacterial, fungal and viral) and the development and institution of preventive strategies to minimize the development and spread of resistance. The journal is specifically concerned with the epidemiology of antibiotic resistance and the mechanisms of resistance development and diffusion in both hospitals and the community. The manuscript management system is completely online and includes a very quick and fair peerreview system, which is all easy to use. Visit http://www.dovepress.com/ testimonials.php to read real quotes from published authors. 